\title{
Some Fixed Point Theorems for Certain Contractive Mappings on Metric and Generalized Metric Spaces
}

\author{
Amit SingH*, M.S. Khan ANd Brian Fisher
}

\begin{abstract}
In the present paper we obtain sufficient conditions for the existence of a unique fixed point of Reich and Rhoades type contractive conditions on generalized, complete, metric spaces dependent on another function. Our results generalize and extend some well-known previous results.
\end{abstract}

\section{INTRODUCTION AND PRELIMINARIES}

The fixed point theorem most frequently cited in the literature is the Banach contraction mapping principle (see [4] or [6]), which asserts that if $(X, d)$ is a complete metric space and $S: X \rightarrow X$ is a contractive mapping, i.e., there exists $k \in[0,1)$ such that for all $x, y \in X$,

$$
d(S x, S y) \leq k d(x, y) \text {. }
$$

Then $S$ has a unique fixed point.

The above contractive definition implies that $S$ is uniformly continuous. It is natural to ask if there is a contractive definition which does not force $S$ to be continuous. To answer the above question, in 1968 Kannan [5] established a fixed point theorem for mappings satisfying the inequality:

$$
d(S x, S y) \leq \lambda[d(x, S x)+d(y, S y)]
$$

for all $x, y \in X$, where $\lambda \in\left[0, \frac{1}{2}\right)$.

Kannan's result [5] was followed by a spate of papers containing a variety of contractive definitions in metric spaces. Rhoades [10] in 1977 considered 250 types of contractive definitions and analyzed the relationship between them.

In 2000 Branciari [2] introduced a class of generalized metric spaces by replacing the triangular inequality by similar ones which involve four or more

2010 Mathematics Subject Classification. Primary: 54H25; Secondary: 47H10.

Key words and phrases. Fixed point, contractive mapping, sequently convergent, subsequently convergent.

${ }^{*}$ Corresponding author. 
points instead of three and improved the Banach contraction mapping principle. Recently, Azam and Arshad [1] in 2008 extended Kannan's theorem for this kind of generalized metric space. In the present paper, we first of all extend Kannan's theorem [5] and then extend the theorem due to Azam and Arshad [1] and [8] for these new classes of functions.

The following definitions will be frequently used in the sequel.

Definition 1.1. [8] Let $(X, d)$ be a metric space. A mapping $T: X \rightarrow X$ is said to be sequentially convergent if we have, for every sequence $\left\{y_{n}\right\}$, if $\left\{T y_{n}\right\}$ is convergent then $\left\{y_{n}\right\}$ also is convergent. $T$ is said subsequentially convergent if we have, for every sequence $\left\{y_{n}\right\}$, if $\left\{T y_{n}\right\}$ is convergent then $\left\{y_{n}\right\}$ has a convergent subsequence.

Definition 1.2. [2] Let $X$ be a nonempty set. Suppose that the mapping $d: X \rightarrow X$ satisfies:

(i) $d(x, y) \geq 0$, for all $x, y \in X$ and $d(x, y)=0$ if and only if $x=y$;

(ii) $d(x, y)=d(y, x)$ for all $x, y \in X$;

(iii) $d(x, y) \leq d(x, w)+d(w, z)+d(z, y)$ for all $x, y \in X$ and for all distinct points $w, z \in X-\{x, y\}$ (the rectangular property).

Then $d$ is said to be a generalized metric and $(X, d)$ is said to be a generalized metric space.

Definition 1.3. Let $\left\{x_{n}\right\}$ be a sequence in $X$ and let $x$ be a point in $X$.

(i) If for every $\epsilon>0$ there is an $n_{0} \in N$ such that $d\left(x_{n}, x\right)<\epsilon$ for all $n>n_{0}$ then $\left\{x_{n}\right\}$ is said to be convergent, $\left\{x_{n}\right\}$ converges to $x$ and $x$ is the limit of $\left\{x_{n}\right\}$. We denote this by $\lim _{n} x_{n}=x$ or by $x_{n} \rightarrow x$ as $n \rightarrow \infty$.

(ii) If for every $\epsilon>0$ there is an $n_{0} \in N$ such that $d\left(x_{n}, x_{m}\right)<\epsilon$ for all $m, n>n_{0}$, then $\left\{x_{n}\right\}$ is said to be a Cauchy sequence in $X$.

(iii) If every Cauchy sequence is convergent in $X$, then $X$ is said to be a complete generalized metric space.

Remark 1.1. [2]

(i) $d\left(a_{n}, y\right) \rightarrow d(a, y)$ and $d\left(x, a_{n}\right) \rightarrow d(x, a)$ whenever $\left\{a_{n}\right\}$ is a sequence in $X$ and $\left\{a_{n}\right\}$ converges to $a \in X$.

(ii) $X$ becomes a Hausdorff topological space with neighbourhood basis given by

$$
B=\{B(x, r): x \in X, r \in(0, \infty)\},
$$

where

$$
b(x, r)=\{y \in X: d(x, y)<r\} .
$$

\section{Fixed Point Theorems on Metric Spaces}

Theorem 2.1. Let $(X, d)$ be a complete metric space and let $T, S: X \rightarrow$ $X$ be mappings such that $T$ is continuous, one-to-one and subsequentially 
convergent and satisfies the inequality

$$
d(T S x, T S y) \leq a d(T x, T S x)+b d(T y, T S y)+c d(T x, T y)
$$

for all $x, y \in X$ and $a, b, c \geq 0$ with $a+b+c<1$, then $S$ has a unique fixed point. Also, if $T$ is sequentially convergent, then for every $x_{0} \in X$, the sequence of iterates $\left\{S^{n} x_{0}\right\}$ converges to $x_{0}$.

Proof. Let $x_{0}$ be an arbitrary point in $X$. We define the iterative sequence $\left\{x_{n}\right\}$ by $x_{n+1}=S x_{n}=S^{n+1} x_{0}$ for $n=0,1,2, \ldots$ Using inequality (3), we have

$$
\begin{aligned}
d\left(T x_{n}, T x_{n+1}\right) & =d\left(T S x_{n-1}, T S x_{n}\right) \\
& \leq a d\left(T x_{n-1}, T S x_{n-1}\right)+b d\left(T x_{n}, T S x_{n}\right)+c d\left(T x_{n-1}, T x_{n}\right) \\
& \leq a d\left(T x_{n-1}, T x_{n}\right)+b d\left(T x_{n}, T x_{n+1}\right)+c d\left(T x_{n-1}, T x_{n}\right),
\end{aligned}
$$

which implies that

$$
(1-b) d\left(T x_{n}, T x_{n+1}\right) \leq(a+c) d\left(T x_{n-1}, T x_{n}\right) .
$$

Putting $h=\frac{a+c}{1-b}$, it follows that

$$
\begin{aligned}
d\left(T x_{n}, T x_{n+1}\right) & \leq h d\left(T x_{n-1}, T x_{n}\right) \leq h^{2} d\left(T x_{n-2}, T x_{n-1}\right) \\
& \leq \ldots \leq h^{n} d\left(T x_{0}, T x_{1}\right) .
\end{aligned}
$$

Hence, for every $m, n \in N$ with $m>n$, we have

$$
\begin{aligned}
d\left(T x_{m}, T x_{n}\right) & \leq d\left(T x_{m}, T x_{m-1}\right)+d\left(T x_{m-1}, T x_{m-2}\right)+\ldots+d\left(T x_{n+1}, T x_{n}\right) \\
& \leq\left(h^{m-1}+h^{m-2}+\ldots+h^{n}\right) d\left(T x_{0}, T x_{1}\right) \\
& \leq \frac{h^{n}}{1-h} d\left(T x_{0}, T x_{1}\right) .
\end{aligned}
$$

Letting $m, n \rightarrow \infty$ in (5), we see that $\left\{T x_{n}\right\}$ is a Cauchy sequence in $X$. By the completeness of $X$, there exists a point $v \in X$ such that

$$
\lim _{n \rightarrow \infty} T x_{n}=v .
$$

Since $T$ is subsequentially convergent, $\left\{x_{n}\right\}$ has a convergent subsequence $\left\{x_{n(k)}\right\}_{k=1}^{\infty}$ a point $u \in X$ such that $\lim _{k \rightarrow \infty} x_{n(k)}=u$.

Since $T$ is continuous and $\lim _{k \rightarrow \infty} x_{n(k)}=u$ it follows that $\lim _{k \rightarrow \infty} T x_{n(k)}=T u$. By (6), we conclude that $T u=v$.

We also have

$$
\begin{gathered}
d(T S u, T u) \leq d\left(T S u, T S^{n(k)} x_{0}\right)+d\left(T S^{n(k)} x_{0}, T S^{n(k)+1} x_{0}\right)+d\left(T S^{n(k)+1} x_{0}, T u\right) \\
\leq a d(T u, T S u)+b d\left(T S^{n(k)-1} x_{0}, T S^{n(k)} x_{0}\right)+c d\left(T u, T S^{n(k)-1} x_{0}\right) \\
+h^{n(k)} d\left(T x_{0}, T S x_{0}\right)+d\left(T x_{n(k)+1}, T u\right) .
\end{gathered}
$$


Therefore,

$$
\begin{gathered}
(1-a) d(T S u, T u) \leq b d\left(T S^{n(k)-1} x_{0}, T S^{n(k)} x_{0}\right)+c d\left(T u, T S^{n(k)-1} x_{0}\right) \\
+h^{n(k)} d\left(T x_{0}, T S x_{0}\right)+d\left(T x_{n(k)+1}, T u\right)
\end{gathered}
$$

and so

$$
\begin{aligned}
d(T S u, T u) \leq & \frac{b}{1-a} d\left(T x_{n(k)-1}, T x_{n(k)}\right)+\frac{c}{1-a} d\left(T u, T x_{n(k)-1}\right) \\
& \quad+\frac{h^{n(k)}}{1-a} d\left(T x_{0}, T x_{1}\right)+\frac{1}{1-a} d\left(T x_{n(k)+1}, T u\right) \\
\rightarrow & 0 \quad \text { as } \quad k \rightarrow \infty .
\end{aligned}
$$

Hence $d(T S u, T u)=0$, which implies that $T S u=T u$. Since $T$ is one to one, we have $S u=u$ and so $S$ has a fixed point $u$.

To prove the uniqueness of $u$, let $v$ be a second fixed point of $S$. Then from injectivity of $T$, we get $S u=S v$, proving the uniqueness of the fixed point.

Finally, suppose that $T$ is sequentially convergent. Then replacing $(n(k))$ by n, we conclude that $\lim _{n \rightarrow \infty} S^{n} x_{0}=u$. This shows that $\left\{S^{n} x_{0}\right\}$ converges to the fixed point of $S$.

Corollary 2.1. Let $(X, d)$ be a complete metric space and let $T, S: X \rightarrow$ $X$ be mappings such that $T$ is continuous, one-to-one and subsequentially convergent. If $\lambda \in\left[0, \frac{1}{2}\right)$ and

$$
d(T S x, T S y) \leq \lambda[d(T x, T S x)+d(T y, T S y)]
$$

for all $x, y \in X$, then $S$ has a unique fixed point. Further, if $T$ is sequentially convergent, then for every $x_{0} \in X$, the sequence of iterates $\left\{S^{n} x_{0}\right\}$ converges to this fixed point.

Remark 2.1. By taking $T x \equiv x$ in Theorem 2.1, we can conclude the Reich's theorem [9].

Remark 2.2. By taking $T x \equiv x$ in Corollary 2.1, we can conclude the Kannan's theorem [5].

The following example shows that Theorem 2.1 and Corollary 2.1 are indeed proper extensions of Kannan's theorem.

Example 2.1. [8] Let $X=\{0\} \cup\left\{4^{-1}, 5^{-1}, 6^{-1}, \ldots\right\}$ endowed with the Euclidean metric. Define $S: X \rightarrow X$ by $S(0)=0$ and $S\left(n^{-1}\right)=(n+1)^{-1}$ for all $n \geq 4$. Obviously the condition (2) is not true for every $\lambda>0$ and so we cannot use the Kannan's theorem [5]. By defining $T: X \rightarrow X$ by 
$T(0)=0$ and $S\left(n^{-1}\right)=n^{-n}$ for all $n \geq 4$ we have, for $m, n \in N(m>n)$, $\left|T S\left(m^{-1}\right), T S\left(n^{-1}\right)\right|=(n+1)^{-n-1}-(m+1)^{-m-1}$

$$
\begin{aligned}
& <(n+1)^{-n-1} \leq 3-1\left[n^{-n}-(n+1)^{-n-1}\right] \\
& \leq 3^{-1}\left[n^{-n}-(n+1)^{-n-1}+m^{-m}-(m+1)^{-m-1}\right] \\
& =3^{-1}\left[\left|T\left(n^{-1}\right)-T S n^{-1}\right|+\left|T\left(m^{-1}\right)-T S m^{-1}\right|\right] .
\end{aligned}
$$

The inequality (8) shows that (7) is true for $\lambda=3^{-1}$. Therefore by Corollary 2.1, $S$ has a unique fixed point.

Similarly, we can prove the following theorem.

Theorem 2.2. Let $(X, d)$ be a complete metric space and let $T, S: X \rightarrow$ $X$ be mappings such that $T$ is continuous, one-to-one and subsequentially convergent and satisfies the inequality

$$
d(T S x, T S y) \leq a d(T x, T S y)+b d(T y, T S x)+c d(T x, T y)
$$

for all $x, y \in X, a, b, c \geq 0$ with $a+b+c<1$, then $S$ has a unique fixed point. Also if $T$ is sequentially convergent then for every $x_{0} \in X$, the sequence of iterates $\left\{S^{n} x_{0}\right\}$ converges to this fixed point.

\section{Fixed Point Theorems on Generalized Metric Spaces}

Theorem 3.1. Let $(X, d)$ be a complete generalized metric space and let $T, S: X \rightarrow X$ be mappings such that $T$ is continuous, one-to-one and subsequentially convergent and satisfies the inequality

$$
d(T S x, T S y) \leq a d(T x, T S x)+b d(T y, T S y)+c d(T x, T y)
$$

for all $x, y \in X, a, b, c \geq 0$ with $a+b+c<1$, then $S$ has a unique fixed point. Also if $T$ is sequentially convergent, then for every $x_{0} \in X$, the sequence of iterates $\left\{S^{n} x_{0}\right\}$ converges to this fixed point.

Proof. Let $x_{0}$ be any arbitrary point in $X$ and put $x_{1}=T x_{0}$. If $x_{0}=T x_{0}$, this means that $x_{0}$ is a fixed point of $T$ and there is nothing to prove.

Assume that $x_{1} \neq x_{0}$ and put $x_{2}=T x_{1}$. Proceeding in this way, we can define the iterative sequence of points in $X$ as follows:

$$
x_{n+1}=S x_{n}=S^{n+1} x_{0}, x_{n} \neq x_{n+1} n=0,1,2, \ldots
$$

Using inequality(10), we have

$$
\begin{aligned}
d\left(T x_{n}, T x_{n+1}\right) & =d\left(T S x_{n-1}, T S x_{n}\right) \\
& \leq a d\left(T x_{n-1}, T S x_{n-1}\right)+b d\left(T x_{n}, T S x_{n}\right)+c d\left(T x_{n-1}, T x_{n}\right) \\
& \leq a d\left(T x_{n-1}, T x_{n}\right)+b d\left(T x_{n}, T x_{n+1}\right)+c d\left(T x_{n-1}, T x_{n}\right),
\end{aligned}
$$

implying that

$$
(1-b) d\left(T x_{n}, T x_{n+1}\right) \leq(a+c) d\left(T x_{n-1}, T x_{n}\right),
$$


and so

$$
d\left(T x_{n}, T x_{n+1}\right) \leq h d\left(T x_{n-1}, T x_{n}\right),
$$

where

$$
h=\frac{a+c}{1-b}<1 .
$$

We can also suppose that $x_{0}$ is not a periodic point. In fact if $x_{n}=x_{0}$, then

$$
\begin{aligned}
d\left(T x_{0}, T x_{1}\right) & =d\left(T x_{0}, T S x_{0}\right)=d\left(T x_{n}, T S x_{n}\right)=d\left(T S^{n} x_{0}, T S^{n+1} x_{0}\right) \\
& \leq h d\left(T S^{n-1} x_{0}, T S^{n} x_{0}\right) \leq h^{2} d\left(T S^{n-2} x_{0}, T S^{n-1} x_{0}\right) \\
& \leq \ldots \leq h^{n} d\left(T x_{0}, T S x_{0}\right) .
\end{aligned}
$$

Since $h<1$, it follows that $x_{0}$ is a fixed point of $\mathrm{S}$. Thus in the sequel of the proof, we can suppose that $S^{n} x_{0} \neq x_{0}$ for $n=1,2, \ldots$

Now inequality (10) implies that

$$
\begin{aligned}
d\left(T x_{n}, T x_{n+m}\right)=d\left(T S^{n} x_{0}, T S^{n+m} x_{0}\right) \\
\leq a d\left(T S^{n-1} x_{0}, T S^{n} x_{0}\right)+b d\left(T S^{n+m-1} x_{0}, T S^{n+m} x_{0}\right) \\
+c d\left(T S^{n-1} x_{0}, T S^{n+m-1} x_{0}\right) \\
\leq a d\left(T S^{n-1} x_{0}, T S^{n} x_{0}\right)+b d\left(T S^{n+m-1} x_{0}, T S^{n+m} x_{0}\right) \\
+c\left[d\left(T S^{n-1} x_{0}, T S^{n} x_{0}\right)+d\left(T S^{n} x_{0}, T S^{n+m} x_{0}\right)\right. \\
\left.+d\left(T S^{n+m} x_{0}, T S^{n+m-1} x_{0}\right)\right] .
\end{aligned}
$$

Hence

$$
\begin{aligned}
(1-c) d\left(T x_{n}, T x_{n+m}\right) \leq & (a+c) d\left(T S^{n-1} x_{0}, T S^{n} x_{0}\right) \\
& +(b+c) d\left(T S^{n+m-1} x_{0}, T S^{n+m} x_{0}\right)
\end{aligned}
$$

and so

$$
\begin{aligned}
d\left(T x_{n}, T x_{n+m}\right) \leq & h d\left(T S^{n-1} x_{0}, T S^{n} x_{0}\right) \\
& +\frac{b+c}{1-c} d\left(T S^{n+m-1} x_{0}, T S^{n+m} x_{0}\right) \\
\leq & h^{n} d\left(T x_{0}, T x_{1}\right)+\frac{b+c}{1-c} h^{n+m-1} d\left(T x_{0}, T x_{1}\right) .
\end{aligned}
$$

Therefore, $d\left(T x_{n}, T x_{n+m}\right) \rightarrow 0$ as $n \rightarrow \infty$. This implies that $\left\{T x_{n}\right\}$ is a Cauchy sequence in $X$. Since $X$ is complete, there exists a point $u \in X$ such that $\lim _{n \rightarrow \infty} T x_{n}=u$.

By the rectangular property, we have

$$
\begin{gathered}
d(T S u, T u) \leq d\left(T S u, T S^{n} x_{0}\right)+d\left(T S^{n} x_{0}, T S^{n+1} x_{0}\right)+d\left(T S^{n+1} x_{0}, T u\right) \\
\leq a d(T u, T S u)+b d\left(T S^{n-1} x_{0}, T S^{n} x_{0}\right)+c d\left(T u, T S^{n-1} x_{0}\right) \\
+h^{n} d\left(T x_{0}, T S x_{0}\right)+d\left(T x_{n+1}, T u\right) .
\end{gathered}
$$


Therefore,

$$
\begin{gathered}
(1-a) d(T S u, T u) \leq b d\left(T S^{n-1} x_{0}, T S^{n} x_{0}\right)+c d\left(T u, T S^{n-1} x_{0}\right) \\
+h^{n} d\left(T x_{0}, T S x_{0}\right)+d\left(T x_{n+1}, T u\right)
\end{gathered}
$$

and so

$$
\begin{aligned}
d(T S u, T u) \leq & \frac{b}{1-a} d\left(T S^{n-1} x_{0}, T S^{n} x_{0}\right)+\frac{c}{1-a} d\left(T u, T S^{n-1} x_{0}\right) \\
& +\frac{h^{n}}{1-a} d\left(T x_{0}, T S x_{0}\right)+\frac{1}{1-a} d\left(T x_{n+1}, T u\right) \\
= & \frac{b}{1-a} d\left(T x_{n-1}, T x_{n}\right)+\frac{c}{1-a} d\left(T u, T x_{n-1}\right) \\
& +\frac{h^{n}}{1-a} d\left(T x_{0}, T x_{1}\right) \\
& +\frac{1}{1-a} d\left(T x_{n+1}, T u\right) .
\end{aligned}
$$

Letting $n \rightarrow \infty$ and using Remark 1.1, we have $T S u=T u$. Since $T$ is one to one, we have $S u=u$. and so $S$ has a fixed point.

To prove uniqueness, let $v$ be another fixed point of $S$. Then by (10), we have

$$
\begin{aligned}
d(T v, T u) & =d(T S v, T s u) \\
& \leq a d(T S v, T v)+b d(T S u, T u)+c d(T v, T u) \\
& \leq \frac{a}{1-c} d(T v, T v)+\frac{b}{1-c}(T u, T u)=0 .
\end{aligned}
$$

Hence $T v=T u$ and so $u=v$. The fixed point is therefore unique.

Finally, if $T$ is sequentially convergent, we conclude that $\lim _{n \rightarrow \infty} S^{n} x_{0}=$ $u$. This shows that $\left\{S^{n} x_{0}\right\}$ converges to the fixed point of $S$.

Corollary 3.1. Let $(X, d)$ be a complete generalized metric space and let $T, S: X \rightarrow X$ be mappings such that $T$ is continuous, one-to-one and subsequentially convergent. If $\lambda \in\left[0, \frac{1}{2}\right)$ and

$$
d(T S x, T S y) \leq \lambda[d(T x, T S x)+d(T y, T S y)]
$$

for all $x, y \in X$, then $S$ has a unique fixed point. Further, if $T$ is sequentially convergent then for every $x_{0} \in X$, the sequence of iterates $\left\{S^{n} x_{0}\right\}$ converges to this fixed point.

Remark 3.1. By taking $T x \equiv x$ in Theorem 3.1, we can conclude the Reich's theorem [9].

Remark 3.2. By taking $T x \equiv x$ in Corollary 3.1 , we can conclude the Kannan's theorem [5]. 
Example 3.1. [1] Let $X=\{1,2,3,4\}$. Define $d: X \times X \rightarrow R$ as follows:

$$
\begin{aligned}
& d(1,2)=d(2,1)=3, \\
& d(2,3)=d(3,2)=d(1,3)=d(3,1)=1, \\
& d(1,4)=d(4,1)=d(2,4)=d(4,2)=d(3,4)=d(4,3)=4 .
\end{aligned}
$$

Obviously $(X, d)$ is a generalized metric space but not a metric space.

The following example shows that Theorem 3.1 and Corollary 3.1 are indeed a proper extensions of Azam and Arshad theorem [1].

Example 3.2. Define a mapping $S: X \rightarrow X$ as follows:

$$
S x= \begin{cases}2, & \text { if } x \neq 1, \\ 4, & \text { if } x=1 .\end{cases}
$$

Obviously the inequality (2) does not holds for $S$ and every $\lambda \in\left[0, \frac{1}{2}\right)$, and so we cannot use the Azam and Arshad theorem for $S$.

Now define $T: X \rightarrow X$ by

$$
T x= \begin{cases}2, & \text { if } x=4 \\ 3, & \text { if } x=2, \\ 4, & \text { if } x=1 \\ 1, & \text { if } x=3\end{cases}
$$

and so

$$
T S x= \begin{cases}3, & \text { if } x \neq 1 \\ 2, & \text { if } x=1\end{cases}
$$

It follows that

$$
d(T S x, T S y) \leq \frac{1}{3}[d(T x, T S x)+d(T y, T S y)] .
$$

Therefore by Corollary 3.1, $S$ has a unique fixed point.

Similarly, we can prove the following theorem:

Theorem 3.2. Let $(X, d)$ be a complete generalized metric space and let $T, S: X \rightarrow X$ be mappings such that $T$ is continuous, one-to-one and subsequentially convergent and satisfies the inequality

$$
d(T S x, T S y) \leq a d(T x, T S y)+b d(T y, T S x)+c d(T x, T y)
$$

for all $x, y \in X$, where $a, b, c \geq 0$ and $a+b+c<1$, then $S$ has a unique fixed point. Further, if $T$ is sequentially convergent, then for every $x_{0} \in X$, the sequence of iterates $\left\{S^{n} x_{0}\right\}$ converges to this fixed point.

Acknowledgement. The authors would like to thank the editor of the paper and the referees for their careful reading of the paper. 


\title{
REFERENCES
}

[1] A. Azam and M. Arshad, Kannan fixed point theorem on generalized metric spaces, J. Nonlinear Sci. Appl., 1(1)(2008), 45-48.

[2] A. Branciari, A fixed point theorem of Banach-Caccippoli type on a class of generalized metric spaces, Publ. Math. Debrecen, 57(1-2) (2000), 31-37.

[3] S.K. Chatterjea, Fixed point theorems, C.R. Acad. Bulgare Sci., 25(1972), 727-730.

[4] K. Goebel and W. A. Kirk, Topics in Metric Fixed Point Theory, Cambridge University Press, New York, 1990.

[5] R. Kannan, Some results on fixed points, Bull. Calcutta Math. Soc., 60(1968), 71-76.

[6] R. Kannan, Some results on fixed points II, Amer. Math. Monthly, 76(1969), 405-408.

[7] M.A. Khamsi and W. A. Kirk, An introduction to metric spaces and fixed point theory, John Wiley and Sons, Inc., 2001.

[8] S. Moradi, Kannan fixed-point theorem on complete metric spaces and on generalized metric spaces depended an another function, arXiv:0903.1577v1 [math.FA] 9 Mar 2009.

[9] S. Reich, Some remarks concerning contraction mappings, Canad. Math. Bull., 14(1971), 121-124.

[10] B.E. Rhoades, A Comparison of Various Definitions of Contractive Mappings, Trans. Amer. Math. Soc. 226(1977), 257-290.

\author{
Amit Singh \\ Department of Mathematics \\ Government Degree College Billawar \\ JAMMU AND KASHMIR \\ INDIA-184204 \\ E-mail address: singhamit841@gmail.com
}

\section{M.S. KHAN}

College of Science

Department of Mathematics and Statistics

Sultan Qaboos University

Post Box 36, Postal Code 123

Al-Khod, Muscat

Sultanate OF OMAN

E-mail address: mohammad@squ.edu.om

\section{Brian Fisher}

Department Of Mathematics

UNIVERSITY OF LEICESTER

LeICESTER, LE1 7RH

ENGLAND

E-mail address: fbr@le.ac.uk 